\section{- \\ ARPA-E sees some success from basic energy research to societal impact}

$\mathrm{M}$ oving promising scientific outcomes from basic research to real societal impact is both capital-intensive and time-consuming. Add to these challenges an existing infrastructure and widely adopted incumbent technologies, and it is easy to understand why technology advancements within the energy sector often fall short of large-scale market adoption. While a wide range of new discoveries in the energy sector show significant promise, "the translation of these discoveries to impactful technologies requires much more than the basic discovery - and a thoughtful approach to evaluating and de-risking them is required since no one has infinite resources to pursue them

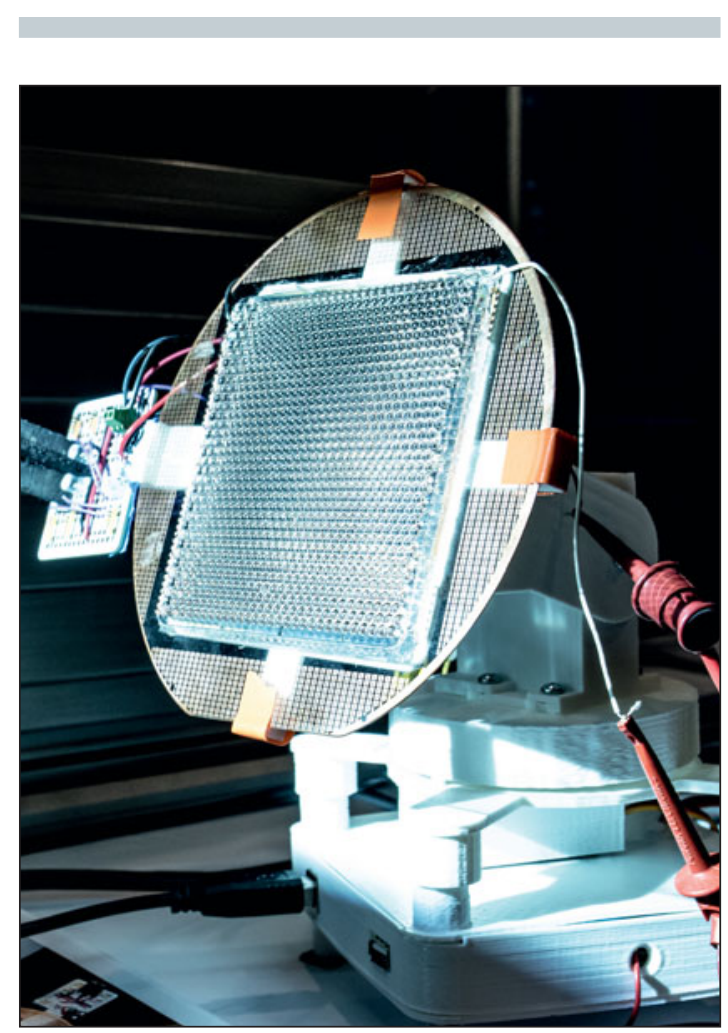

A prototype hybrid microscale concentrated photovoltaic (micro-CPV) solar array developed for an ARPA-E project. Image courtesy of U.S. Department of Energy. all," says Mark Hartney, CTO of SLAC National Accelerator Laboratory.

The Advanced Research Projects Agency-Energy (ARPA-E) was created to address the challenges in proving out promising results of basic research to rapidly move forward with technology advancements that have the potential to impact society. Established within the US Department of Energy (DOE) in 2007 and first funded in 2009, ARPA-E is authorized to "overcome the longterm and high-risk technological barriers in the development of energy technologies." Modeled on the successful Defense Advanced Research Projects Agency (DARPA), ARPA-E was created to enable the United States to maintain technological lead across the energy sector with specific focus on decreasing energy imports, reducing energy-related emissions, and improving energy efficiency.

Programs within ARPA-E consist of a collection of related projects that are led by teams of scientists, engineers, and entrepreneurs - a public/private partnership. According to Eric Schiff, ARPA-E program director, the programs are not simply funding sources but "efforts at thought leadership." Schiff says that the programs "identify important areas for energy research investment and provide credible scientific and engineering rationales for this investment." Each project is evaluated quarterly against technical milestones to assess progress.

"Materials innovation is a key theme across many of the activities at ARPA-E," says Paul Albertus, ARPA-E program director; about half of all ARPA-E programs depend on materials-related discoveries and advancements (see MRS Bulletin, May 2017). Albertus also points out that support such as that provided by ARPA-E is especially important in materials science because "materials development remains time-intensive and expensive, and true breakthroughs are few and far between, making industrial support very limited."

ARPA-E's structure and research program requirements are set up to help bridge the gap between the promising discovery in the laboratory and the point when the new energy technology can attract follow-on funding. Program directors, fellows, and tech-to-market advisors are hired from across the energy sector-academia, national laboratories, and industry - to provide expertise over a limited term, usually three years.

Program directors are typically established researchers who create and manage programs as well as provide assessments of whether a project is on track, should be pivoted to a new direction, or terminated. Fellows are generally early stage researchers and serve as an "internal think tank for the agency [to] help identify new program ideas," says Kristen Brown, a former ARPA-E Fellow. Tech-to-market advisors often come from energy industries and use their expertise to guide ARPA-E projects to commercial viability by advising on intellectual property, fundraising, outreach, and relationships.

Hartney, a former ARPA-E program director, says that the structure of ARPA-E and its ability to convene experts across the energy sector allows it to pursue "early stage validation of high-risk but potentially high-impact technologies." Albertus agrees, saying that ARPA-E's project structure is "unique" because it is "deeply rooted in science and technical sophistication, while including a focus on translation and an empowered principal investigator with the resources needed to pursue risky but high-reward ideas."

The ARPA-E mantra is "If it works, will it matter?"- and every research program is shaped and evaluated on its potential for eventual societal impact. Schiff characterizes most ARPA-E projects as 
"very early stage but application-driven," and says that they "fall in the valley between curiosity-driven fundamental research, which might be supported by the National Science Foundation [or another government agency], and product-driven research that is supported by industry." Hartney also highlights the important role that ARPA-E plays in funding and proving out early stage energy technology ideas that "will then stimulate further private investment or point back to other promising approaches to pursue."

Indeed, despite being a relatively young agency, ARPA-E boasts some significant success. The National Academy of Sciences (NAS) completed an independent review of ARPA-E (mandated within ARPA-E's 2007 authorizing statute) in June 2017 and its summary states, "There are clear indicators that ARPA-E is making progress toward achieving its statutory mission and goals, and it cannot reasonably be expected to have completely fulfilled those goals given so few years of operation and the size of its budget."

The NAS report based its findings on ARPA-E data from February 2017, when the agency had provided approximately $\$ 1.5$ billion in funding to more than 580 projects. As these projects matured, 56 have gone on to form new companies, 68 have led to partnerships with other government agencies for further development, and 74 have gone on to attract more than $\$ 1.8$ billion in private-sector follow-on funding. In addition, over 1300 peer-reviewed journal articles and 208 patents have been generated as a result of ARPA-E projects.

Despite the success of ARPA-E, the agency has recently become a focus of debate within the US government. The Trump administration's budget request for fiscal year 2018 (FY2018) has called for complete elimination of ARPA-E. In the US Congress, lines are drawn between the House and Senate because the House's FY2018 energy appropriations bill aligns with the administration's request and eliminates funding for ARPA-E, while the Senate's version proposes a budget of \$330 million-an $8 \%$ increase from the FY2017 enacted (appropriated) funding level. Senator Lamar Alexander (R-Tenn.), Chair of the Senate Energy and Water Development Appropriations Subcommittee, has been a strong supporter of ARPA-E, and during a recent hearing on the DOE budget he characterized ARPA-E as a "big success" and responded to the idea of eliminating it by saying, "that is not what we're going to do."

"One danger of even posturing the closure of ARPA-E is the signal it sends to a community that's already strapped for funding," Brown says. With budget negotiations dragging despite the fact that FY2018 officially started on October 1, 2017, the fate of ARPA-E and the important early stage research it funds continues to hang in the balance.

Jennifer A. Nekuda Malik
South Africa needs research plan for shale gas exploitation

$\mathrm{S}$ outh Africa needs a shale gas research plan aligned to government policy and included into the broader government research program driven by various departments and agencies, according to federal agencies.

Phil Mjwara, Director-General of the Department of Science and Technology (DST), told delegates at a conference on shale gas under way in Port Elizabeth in August, that the research plan could help develop expertise related to shale gas exploitation in South Africa.

The objective of the conference, titled "The Shale Gas Industry in South Africa: Toward a Science Action Plan," was to highlight critical reports on shale gas in South Africa, analyze the regulatory environment, consolidate common findings and recommendations, and provide a platform for debate.

"Some of the objectives of the plan should be to develop national technical capabilities in key focal areas, including pure science, engineering, and social science associated with shale gas exploitation," Mjwara said.

He added that international experience has shown that shale gas has numerous economic benefits. He pointed out that any scientific plan on shale gas must strike a healthy balance between environmental protection and economic benefit.

The two-day conference, hosted by the Academy of Science of South Africa (ASSAf) in partnership with the DST, followed the publication of ASSAf's report on South Africa's Technical Readiness to Support the Shale Gas Industry, and the Department of Environmental Affairs' report on Shale Gas Development in the Central Karoo: A Scientific Assessment of the Opportunities and Risks.

Cyril O'Connor, from the University of Cape Town, head of the panel of experts for the ASSAf study, said that the amount of shale gas available in South Africa was still unclear, with estimates ranging between 20 trillion cubic feet (tcf) and over 400 tcf. It is thought that substantial volumes of such gas shales can be found in the main Karoo Basin.

He said that since shale gas exploitation requires the use of relatively large quantities of water, greater clarity is needed on the availability of alternative water sources such as underground saltwater.

Furthermore, South Africa is known to possess considerable reserves of shale gas and oil reserves in the Western, Northern, and Eastern Cape rock basin. ASSAf's Vice President, Barney Pityana, said, "This is because of the geology of the area, and the possibilities of economically available and advanced extractive technology mean that this industry is capable of development. It could provide a game changer for the South African economy, and could make a major contribution to South Africa's commitments in terms of climate change by limiting South Africa's reliance on the coal industry for its energy needs." 